Results A total of 155 patients were evaluable; 41.9\% carcinosarcoma, $36.8 \%$ serous, $17.4 \%$ G3 and $3.9 \%$ CC; $67.1 \%$ received chemoradiation, $25.8 \%$ received chemotherapy-alone and $7.1 \%$ received RT-alone. Adjuvant therapy regimens were well-balanced between different histologies $(p=0.351)$. There was no difference in the frequency of treatment delays between regimens $(p=0.571)$. G3 tumors recurred less frequently (66.7\%) versus serous (80.7\%), CC (83.3\%) and carcinosarcoma $(84.6 \%)(\mathrm{p}=0.269)$. Abdominal recurrence occurred most often in CC and serous. Carcinosarcoma was most likely to recur in the lung. There was a trend towards greater retroperitoneal recurrence with chemotherapy-alone (25.9\%) versus chemoradiation (8.4\%) and RT-alone $(7.7 \%)$ $(p=0.252)$. G3 tumors demonstrated improved PFS and OS (26 and 42-months, respectively) versus serous (17 and 30months, respectively), carcinosarcoma (14 and 24-months, respectively) and CC (24 and 30-months respectively) $(p=0.002, p<0.001)$. Chemoradiation was superior to chemotherapy-alone and RT-alone in PFS $(p<0.001)$ and OS $(\mathrm{p}<0.001)$.

Conclusion The majority of stage IIIC HGEC recurs. Chemoradiation was associated with improved survival and less retroperitoneal recurrence versus chemotherapy-alone. G3 tumors demonstrated improved survival compared other histologies regardless of adjuvant treatment modality.

\section{IGCS20 1274}

\section{PRE-OPERATIVE WAIT TIMES IN HIGH RISK ENDOMETRIAL CANCER: DO SURGICAL DELAYS IMPACT PATIENT SURVIVAL?}

${ }^{1} A$ Nica*, ${ }^{2} R$ Sutradhar, ${ }^{3} A$ Covens, ${ }^{3} R$ Kupets, ${ }^{3} D$ Vicus, ${ }^{2} Q$ Li, ${ }^{4} S$ Ferguson, ${ }^{3} L T$ Gien. ${ }^{1}$ University Of Toronto, Canada; ${ }^{2} \mathrm{C} / \mathrm{ES}$, Canada; ${ }^{3}$ Sunnybrook Health Sciences Centre, Canada; ${ }^{4}$ Princess Margaret Cancer Centre, Canada

\subsection{6/ijgc-2020-IGCS.225}

Objectives Practice guidelines advocating for the regionalization of endometrial cancer surgery to gynecologic oncologists (GO) practicing in designated gynecologic oncology centres were released by Cancer Care Ontario in June 2013. We sought to determine the impact this policy had on contemporary surgical wait times, and whether longer wait time to surgery is a predictor of survival in patients with high risk endometrial cancer.
Study Methods This was a retrospective cohort study, which included patients diagnosed with non-endometrioid high-risk endometrial cancer (serous, carcinosarcoma, clear cell, and undifferentiated) between 2003 and 2017. A cut point of January 2014 was chosen to allow 6 months for knowledge translation and define 2 regionalization periods.

Results We identified 3518 patients with high risk endometrial cancer. Patients who had surgery with a GO had a median surgical wait time from diagnosis to hysterectomy of 55 days compared to 59 days pre-regionalization $(\mathrm{p}=0.0002)$, and from first GO consultation to hysterectomy of 29 days compared to 32 days pre-regionalization $(p=0.0006)$. Survival was worst for patients who had surgery within 14 days of diagnosis (HR death 1.94, 95\% CI 1.48-2.54), indicating disease severity. Decreased survival occurred with surgical wait times of more than 45 days from the patient's first GO appointment (HR death 1.19, 95\%CI 1.04-1.36).

Conclusion Regionalization of surgery for high risk endometrial cancer has not had a negative impact on surgical wait times. Impact on survival is seen with patients who have surgery more than 45 days after surgical consultation.

\section{IGCS20_1275}

\section{DISCORDANT MISMATCH REPAIR PROTEIN EXPRESSION IN SYNCHRONOUS ENDOMETRIAL AND OVARIAN CANCERS}

${ }^{1} \mathrm{~S}$ Kim ${ }^{*},{ }^{2} \mathrm{~A}$ Tone, ${ }^{3} \mathrm{~A}$ Pollett, ${ }^{4} \mathrm{R}$ Kim, ${ }^{3} \mathrm{M}$ Cesari, ${ }^{3} \mathrm{~B}$ Clarke, ${ }^{5} \mathrm{~L}$ Eiriksson, ${ }^{6} \mathrm{~T}$ Hart, ${ }^{7} \mathrm{~S}$ Holter, ${ }^{8} \mathrm{~A}$ Lytwyn, ${ }^{9} \mathrm{M}$ Maganti, ${ }^{10} \mathrm{~L}$ Oldfield, ${ }^{10} \mathrm{~T}$ Pugh, ${ }^{11} \mathrm{~S}$ Gallinger, ${ }^{1} \mathrm{M}$ Bernardini, ${ }^{12} \mathrm{~A}$ Oza, ${ }^{3} \mathrm{~V}$ Dube, ${ }^{3} \mathrm{~J}$ Lerner-Ellis, ${ }^{2} \mathrm{E}$ Van de Laar, ${ }^{1} \mathrm{D}$ Vicus, ${ }^{1} \mathrm{~S}$ Ferguson. ${ }^{1}$ Department of Obstetrics and Gynecology, University of Toronto, Canada; ${ }^{2}$ Division of Gynecologic Oncology, Princess Margaret Cancer Centre/University Health Network/Sinai Health Systems, Canada; ${ }^{3}$ Department of Laboratory Medicine and Pathobiology, University of Toronto, Canada; ${ }^{4}$ Fred A Litwin Family Centre for Genetic Medicine, University Health Network, Canada; ${ }^{5}$ Division of Gynecology Oncology, Department of Obstetrics and Gynecology, Juravinski Cancer Centre, McMaster University, Canada; ${ }^{6}$ Department of Psychology, Ryerson University, USA; 'Zane Cohen Centre for Digestive Diseases, Familial Gastrointestinal Cancer Registry, Mount Sinai Hospital, Canada; ${ }^{8}$ Division of Anatomical Pathology, Department of Pathology and Molecular Medicine, McMaster University, Canada; ${ }^{9}$ Department of Biostatistics, Princess Margaret Cancer Centre/University Health Network, University of Toronto, Canada; ${ }^{10}$ Department of Medical Biophysics, University of Toronto, USA;

${ }^{11}$ Division of General Surgery, Princess Margaret Cancer Centre/University Health Network Sinai Health Systems, Canada; ${ }^{12}$ Division of Medical Oncology and Hematology, Princess Margaret Cancer Centre/University Health Network/Sinai Health Systems, Canada

10.1136/ijgc-2020-IGCS.226

Abstract 263 Table 1 Concordance of mismatch repair (MMR) immunohistochemistry (IHC) and microsatellite instability (MSI) results between ovary and endometrium for five cases with Lynch syndrome

\begin{tabular}{|c|c|c|c|c|c|c|c|}
\hline Case & $\begin{array}{c}\text { Germline } \\
\text { Mutation }\end{array}$ & $\begin{array}{c}\text { MMR IHC in } \\
\text { Ovary }\end{array}$ & $\begin{array}{c}\text { MMR IHC in } \\
\text { Endometrium }\end{array}$ & MSI in Ovary & $\begin{array}{c}\text { MSI in } \\
\text { Endometrium }\end{array}$ & $\begin{array}{c}\text { MMR IHC } \\
\text { concordance } \\
\text { between } \\
\text { Ovary and } \\
\text { Endometrium }\end{array}$ & $\begin{array}{c}\text { MSI } \\
\text { Concordance } \\
\text { between } \\
\text { Ovary and } \\
\text { Endometrium }\end{array}$ \\
\hline 1 & MSH6 & $\begin{array}{c}\text { MSH6 } \\
\text { deficient }\end{array}$ & $\begin{array}{c}\text { MSH6 } \\
\text { deficient }\end{array}$ & MSI-H & MSS & $\mathrm{Y}$ & $\mathrm{N}$ \\
\hline 2 & MSH6 & $\begin{array}{c}\text { MSH6 } \\
\text { deficient }\end{array}$ & $\begin{array}{c}\text { MSH6 } \\
\text { deficient }\end{array}$ & MSI-H & MSS & $\mathrm{Y}$ & $\mathrm{N}$ \\
\hline 3 & MLH1 & $\begin{array}{c}\text { MLH1/PMS2 } \\
\text { deficient }\end{array}$ & $\begin{array}{c}\text { MLH1/PMS2 } \\
\text { deficient }\end{array}$ & MSI-H & MSI-H & $\mathrm{Y}$ & $\mathrm{Y}$ \\
\hline 4 & PMS2 & Intact & Intact & MSS & MSS & $\mathrm{Y}$ & $\mathrm{Y}$ \\
\hline 5 & MSH6 & $\begin{array}{c}\text { MSH6 } \\
\text { equivocal }\end{array}$ & $\begin{array}{c}\text { MSH6 } \\
\text { deficient }\end{array}$ & MSI-H & MSI-H & $\mathrm{N}$ & $\mathrm{Y}$ \\
\hline
\end{tabular}

Abbreviations: MSI-H, microsatellite instable; MSS, microsatellite stable 